\title{
A CONCEPT OF TRANSITION TO THE BEST AVAILABLE TECHNOLOGY AS A BASIS FOR SUSTAINABLE DEVELOPMENT OF POWER INDUSTRY
}

\author{
M. BEREZYUK \& A. RUMYANTSEVA \\ Department of Environmental Economics, Ural Federal University, Russia.
}

\begin{abstract}
The high level of the negative impact on the environment in the Russian Federation remains steady for many years. Significant and specific contribution to the current level of pollution is made by the companies of the energy sector, which is among the top three in terms of the negative impact on the environment. The planned transition to technological regulation system is based on the use of the best available technology (BAT). The concept formation of the transition to BAT is a challenge for the industry. The basis of the concept is the unified approach development, harmonized with the European approaches, Russian practice and methodological guidelines for BAT identification, which will facilitate informational and technical implementation of BAT in the economy entities of the energy sector. To solve this problem, the authors developed a model for BAT implementation, using a step-by-step logical approach to decision-making. This approach is based on a comparison of the environmental protection measures effectiveness with costs that the economic entity should bear to avoid or minimize man-made impact in normal conditions of management, that is, before BAT introduction. The economic expediency evaluation of the technology in a particular industry is an integral part of BAT implementation concept.

Keywords: algorithm, best available technologies, concept, ecological effectiveness, economic effectiveness, power industry.
\end{abstract}

\section{INTRODUCTION}

In accordance with the Federal Law no. 219-FZ, 'On Amendments to the Federal Law "On Environmental Protection" and Certain Legislative Acts of the Russian Federation', a gradual transition to the technological regulation system, based on the best available technologies (BATs), using the European Union experience and specifics of the domestic economy began in Russia since January 1, 2015 [1]. Economic entities, operating units with the significant impact level on the environment, will be required to switch to BAT. Thus, the companies face a complicated practical task of choosing a technology for the further modernization.

The goal of this research is the use of a systematic approach to the problem solution and the development of a mechanism to select the best options for the introduction of new technologies based on BAT. The application of the modern resource-saving, innovative technologies enables the usage of new technological equipment with the financial support of the state, as well as the optimization of industrial companies activities by switching to feasible requirements and indicators, established by regulating authorities.

\section{POWER INDUSTRY CONTRIBUTIONS TO THE ENVIRONMENTAL POLLUTION LEVEL OF THE RUSSIAN FEDERATION}

The authors focused their attention on the energy sector due to the dominant contribution of this complex to the pollution of the Russian Federation.

Electric power production in the Russian Federation in 2014 amounted to 1,046 billion $\mathrm{kW} / \mathrm{h}$, the consumption was equal to $1,035.2$ billion $\mathrm{kW} / \mathrm{h}[2]$. 


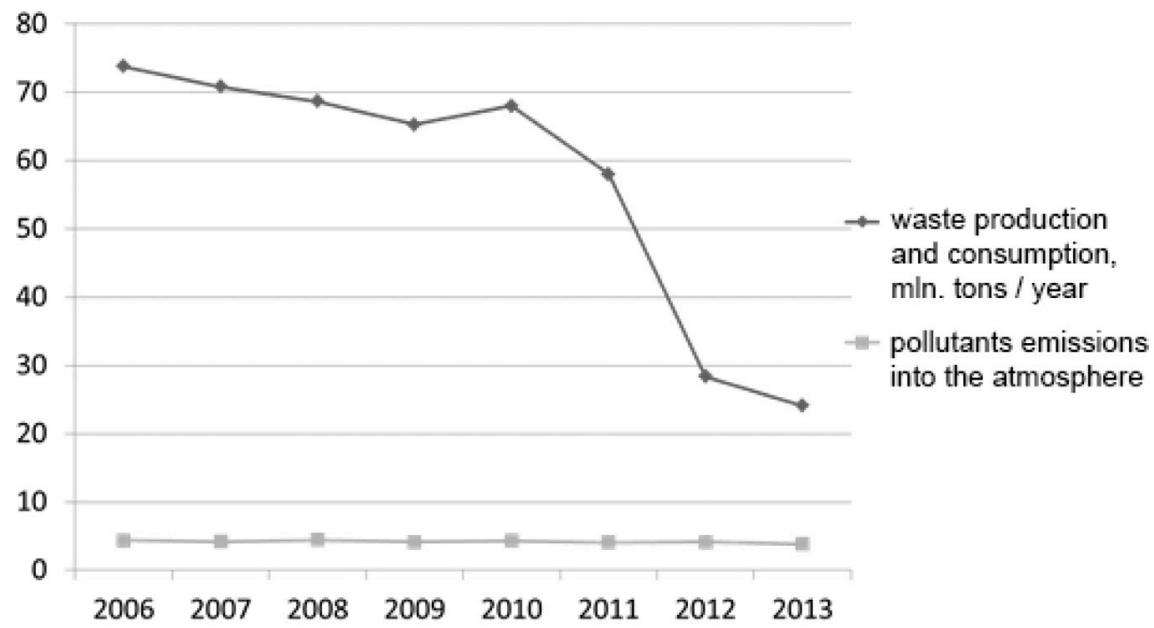

Figure 1: Emission volume of the pollutants, production and consumption of wastes produced by the 'Production and distribution of electricity, gas and water' industry.

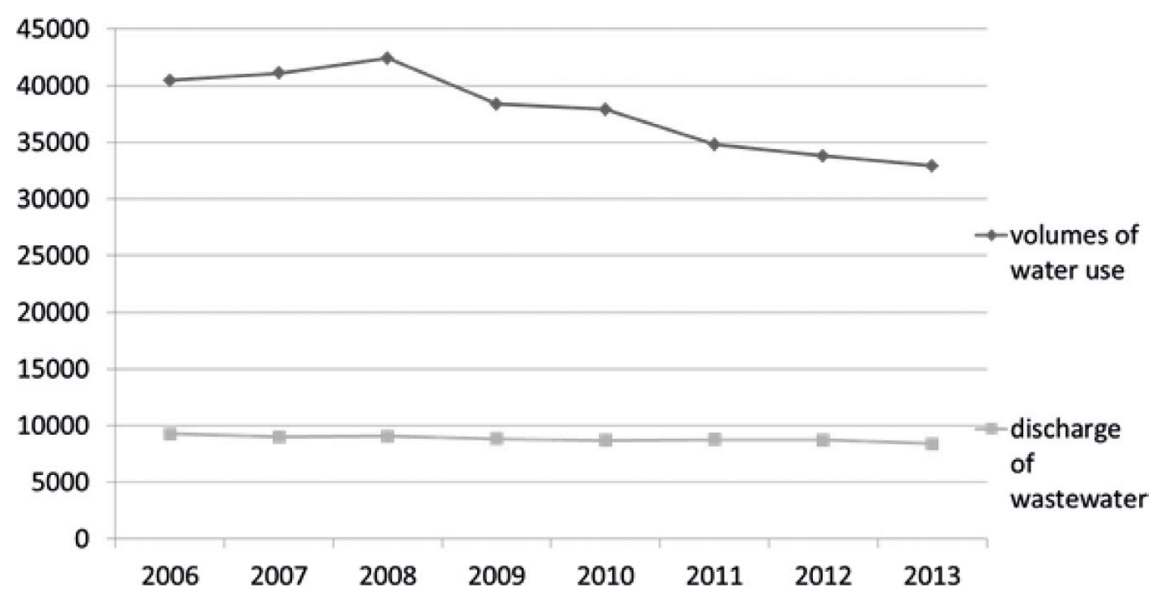

Figure 2: The dynamics of the overall index of water usage and sewage discharge in the 'Production and distribution of electricity, gas and hot water' industry, million m3/year.

Major energy sector companies are classified as units with significant impact on the environment. The volume dynamics of pollutant emissions, sewage discharges, production and consumption of wastes produced by the 'Production and distribution of electricity, gas and water' industry are shown in Fig. 1 [3].

As a part of the Energy Strategy of Russia for the period until 2030 (approved by the Government Decree no.17-15-r of November 13, 2009), the target figures to reduce the volume of the industry negative impact on the environment were developed [4]. It was planned that by 2030, the reduction of specific pollutants emissions into the atmosphere, sewage discharge into water bodies, waste 
generation by power units (in $\%$ to 2005) should not be $<50 \%$ and the providing for the level of greenhouse gas emissions (in \% to 1990) should not exceed $105 \%$.

To reach the set figures, the radical changes in the monitoring approaches to the companies impact on the environment and stimulation of this impact reduction are needed. According to the authors, the transition to the regulation system, based on BAT, can make a significant contribution to the achievement of these goals. The authors consider it rational to give a brief analysis of BAT implementation stages in the Russian Federation.

\section{TRANSITION TO TECHNOLOGICAL REGULATION SYSTEM}

The first strategic act, aimed at the transition to the new regulation system and new environmental safety indexes of companies, was a Presidential Decree no. 889 of July 4, 2008 'On Certain Measures to Improve Energy and Environmental Efficiency'. Subsequently, a number of documents concerning the strategic plans of the Russian Federation to change the current system of state regulation in the field of environmental protection.

The foundation of these changes relies on the principles and provisions of environmental regulation, approved by the European Union Directive on Industrial Emissions 2010/75/UE (IED) (integrated pollution prevention and control, IPPC) [5], instead of the previously used EU Council Directive no. 96/61/EU of 24.09.1996, 'On Integrated Pollution Prevention and Control (IPPC)' [6]. According to the current IED, only big thermal stations with the thermal energy exceeding $50 \mathrm{MW}$ are taken into account, thus excluding the other types of stations such as nuclear or hydroelectric power stations;

From 2002 to 2012, a number of projects forming the basis of the adopted law [1] for transition to the BAT principles were carried out:

- Within the project 'Environmental Standards Harmonization' (2002-2009), an overview of the $\mathrm{EU}$ and the Russian Federation requirements, regarding the issue of permits for emissions, discharges and waste disposal was prepared, the application concept of the BAT was considered and a number of EU documents were translated into Russian.

- In 2009, the Reference Document on Best Available Techniques for Large Combustion Plants (BREF LCP [7]) with the thermal capacity over $50 \mathrm{MW}$ was translated into Russian language [8] and the European practice of development and harmonization of this document was analyzed.

- 'Handbook on the best available techniques to improve efficiency and minimize negative impacts on the environment in the power industry' (2008) was translated [9].

- 'Basic Provisions (Concept) of technical policy in the electric power industry of Russia until 2030' [10] were developed.

- Reference book 'Modern environmental protection technologies in the power industry' [11].

The concept [10] has the main goals and objectives of technological policy in the target vision context of the electric power development strategy until 2030, the policy for electric power systems, thermal power system, heat supply, hydroelectric power and hydraulic structures, RER and electrical equipment. The book [11] contains a detailed description of the best domestic and foreign energy production technologies and detailed information on almost all important questions and environmental issues of the industry.

BREFs (Reference Document on Best Available Techniques), used in the EU, currently describe, in particular, applied technologies, modern levels of emissions and consumption, technologies to determine the BATs, as well as the conclusions on BAT. 
In 2015, the division of the companies into four categories according to the degree of their negative impact on the environment was introduced. The main criterion for the selection of the units, which will get integrated ecological permits after 2019 is their designation to the BAT application [1].

The Russian Federal Government approved a milestone schedule for the BREF reference documents created in 2015-2017. According to the schedule, in the next three years, 47 BREF documents will be developed for priority sectors, including power sector.

According to Article 13 of the IED, in the EU, the European IPPC Bureau of the European Commission organizes information exchange between Member States, industries, non-governmental organizations involved in environmental protection, to create, review and, if necessary, adjust documents relating to BAT. Similar order is planned to be put into effect in Russia. The procedure for the technology relation to BAT is already approved as well as for the development, actualization and publication of the reference technology BREF.

International cooperation in the use of BAT is not limited to EU countries. Changes, made in 2012, in the Protocol of the UN Economic Commission for Europe 'to Abate Acidification, Eutrophication and Ground-level Ozone', signed in Gothenburg (Sweden) in 1999 [12] can be used as an example, of the possible changes in the national legislation, providing transition to BAT. The changes affected the national obligations in emissions reduction that should be achieved by 2020 both inside and outside of the countries. The revised protocol also defines a flexible approach to facilitate the joining of the new Parties, mainly countries of the South and Eastern Europe, the Caucasus and the Central Asia. Another example of the international cooperation in the field of reducing the negative impact on the environment and the general public awareness is the Kiev Protocol on Pollutant Release and Transfer Registers [13]. As of January 7, 2014, the Protocol has been ratified by 32 countries and by the European Union.

The creation of the European Pollutant Release and Transfer Register (E-PRTR) [14] and national PRTR under the Protocol to the Aarhus Convention, greatly facilitates the collection of pollution

Table 1: Stages of transition to the technological regulation system.

\begin{tabular}{|c|c|}
\hline Period & Work stage contents \\
\hline 2015-2017 & $\begin{array}{l}\text { - The division of the companies into four categories according to the } \\
\text { degree of their negative impact on the environment } \\
\text { - State registration of working companies and category conferment } \\
\text { - The development of BREF reference documents }\end{array}$ \\
\hline Since January 2015 & $\begin{array}{l}\text { State regulation measures in the field of environmental protection will } \\
\text { apply only to the pollutants included in the list established by the } \\
\text { Government of the Russian Federation }\end{array}$ \\
\hline 2019-2022 & $\begin{array}{l}\text { The owners of Category I companies, with the contribution to the total } \\
\text { pollutant emissions not less than } 60 \% \text {, are required to apply for an } \\
\text { integrated environmental permit (IEP) }\end{array}$ \\
\hline Since January 1, 2019 & $\begin{array}{l}\text { The coming into force of the legal requirements for the inclusion into } \\
\text { IEP of the mandatory program of eco-efficiency increase and envi- } \\
\text { ronmental protection action plans for the facilities of category II }\end{array}$ \\
\hline Until January 2025 & The rest of the economic entities will have to get IEP \\
\hline
\end{tabular}


data on specific substances, needed, for example, to prepare the government reports about the state of environment and other forms of environmental reporting, and gives a real opportunity to the public to get information about pollution.

Certainly, the Russian Federation, in spite of certain achievements, stands at the beginning of transition to technological regulation, that is why the experience of the EU is carefully studied and adaptation of the EU regulatory framework to the legal field and the economic and technological characteristics of the Russian Federation is carried out.

The planned stages of the transition to technological regulation system are shown in Table 1.

As it was mentioned above, the direct use of European BREFs [8,15] at the Russian companies is hardly possible due to the existing differences in characteristics of all types of resources, peculiarities of raw materials, the availability of different energy types, natural conditions, environmental characteristics of the areas and production technologies. That is why the science-based methodological support should be developed for transition of the Russian energy sector to BAT. An algorithm, consisting of several stages is proposed. The algorithm is original and rather subjective, but it helps to choose the best technologies in accordance with a systematic approach, taking into account economic and environmental components of this process.

\section{APPLICATION OF BAT SELECTION ALGORITHM BY ENERGY-PRODUCING COMPANIES}

To determine BAT, the most effective technology (technical measures, administrative decisions) in terms of achieving a high general level of environmental protection at the energy-producing companies should be chosen.

Stage 1. Current situation at the companies analysis: It is necessary to estimate the current situation at the companies in terms of its impact on the environment. First of all, environmental pollution at the power companies depends on the technology used at the power station, and fuel type that was used to generate energy.

Power stations can be classified according to several criteria:

- Production processes type: thermal, nuclear or hydroelectric power stations. Thermal power stations (TPS) account for $68.4 \%$ of total electricity generation, hydraulic for $20.3 \%$, nuclear for about $11.1 \%$. In practice, the essential part of pollution is produced by TPS, with thermal energy exceeding $50 \mathrm{MW}$.

- Consumed fuel type.

- Degree of negative impact on the environment.

On the basis of the company impact volume on the environmental components, its risk category should be determined from an environmental point of view. The volume of the impact on the environmental components should also be defined, so it would be possible to determine whether the impact of the given company is subject to the BAT regulation [17].

Stage 2. Determine the sphere of application for alternative technologies: At this stage, it is necessary to consider all technologies that can be used to reduce the impact on the environment $[8,15]:(1)$ technological solutions; (2) raw materials selection; (3) production processes control; (4) organizational arrangements; (5) 'non-technical' events; (6) end-of-pipe technology. Preference may be given to existing technologies, which can prevent or reduce pollutant discharges (emissions) into the environment after their modernization (modification), or to the new technologies that will have the lowest impact on the environment. 
It is likely that at this stage, the level of impact on the environment and the possible effects of the technologies introduction will become evident. It will be possible to choose the most appropriate technology $[16,17]$.

Stage 3. Alternative technologies analysis: At this stage, data on pollutant emissions (discharges, wastes production and consumption) as a result of considered technologies application should be analyzed and summarized, as well as the data on used resources. During this stage realization, relevant input and output parameters should be submitted in the form of a list (with quantitative indicators) of the considered technologies. This list should include produced discharges, emissions, wastes, other impacts and consumed materials (water, coal and gas) [17].

Stage 4. Evaluation of all types of environmental impacts: Comparison of the different pollutants is conducted for each of the considered alternative technologies according to seven priority environmental problems: (1) toxicity for people; (2) the toxicity of water bodies; (3) global warming; (4) acid rain formation; (5) eutrophication; (6) ozone layer depletion and (7) probability of tropospheric ozone formation.

The reference book [15] describes the integrated assessment methodology of the technological impact on the environment, which can be used to compare alternatives considered as BAT.

Stage 5. Description of the environmental problems assessment approach (method): Three possible approaches are proposed to evaluate options and get the results on the basis of the fulfilled assessments. Each of the approaches can be used independently or together. The first approach is the most simplified, it compares the previously considered and calculated impacts for each of the seven environmental problems.

The second approach is more complex and allows to compare contributions made by the considered technology for each of the seven environmental issues, with All-European indexes. The third approach allows to compare considered pollutants separately with the data of the E-PRTR $[8,15]$.

These approaches are just tools for making appropriate well-thought administrative decisions on the alternative technologies.

To determine BAT for energy-producing companies, the local issues should be taken into account: climatic and logistic features of stationing and socio-economic development prospect of the area from the perspectives of public and private investments [17].

Stage 6. Analysis of the additional information for alternative technologies description: At this stage, all available additional information to clarify the description of the technology is gathered: technical and economic service time of the equipment, service data (operating rules, consumption of fuel, power, water, etc.). Detailed characteristics will be used to collect and analyze data on costs. Together with the level of impact on the environment, it is necessary to assess the degree of exploitation reliability of considered production systems for the local area. Data recording on comparable indexes can be fulfilled in two ways: in relative numbers (this recording will allow to trap $85 \%$ of substances) and in absolute numbers (with round-the-clock working system, this way allows to make pollutant emission at concentrations $<0.5 \mathrm{mg}$ per $1 \mathrm{~m}^{3}$ ) [17].

After reviewing and ranking the possible options in terms of environmental performance, the variant with the least impact on the environment is considered to be the best, but only if this option is available from the economic point of view. Therefore, after the integrated assessment of impacts on the environment, it is necessary to evaluate and compare the costs of the considered alternative technologies implementation [16]. The following stages will help create an objective database of the costs for fair comparison.

Stage 7. Data collection on the costs of the technologies introduction: All factors that may affect the data accuracy should be taken into account. Certainly, this may affect the evaluation results and the final decision on BAT selection. The main sources of the cost data are: technology or equipment 
Table 2: Cost structure of technologies implementation.

\begin{tabular}{|c|c|}
\hline Costs structure & Costs specification \\
\hline 1 & 2 \\
\hline \multicolumn{2}{|l|}{ 1. Investment costs } \\
\hline $\begin{array}{l}\text { 1.1. Implementation } \\
\text { costs (installation, } \\
\text { equipment) }\end{array}$ & $\begin{array}{l}\text { - Development of technical specifications, project } \\
\text { - Work planning } \\
\text { - Coordination, expertise } \\
\text { - Land purchase. } \\
\text { - Engineer survey costs } \\
\text { - Preparatory work on construction site } \\
\text { - Construction and installation works, including the construction of } \\
\text { buildings and structures, engineering infrastructure } \\
\text { - Contracts placement costs } \\
\text { - Commissioning costs } \\
\text { - Costs on dismantling and demolition of structures (installation, } \\
\text { - equipment) } \\
\text { - Current capital } \\
\text { Decommissioning costs }\end{array}$ \\
\hline $\begin{array}{l}\text { 1.2. Environmental } \\
\text { protection equipment }\end{array}$ & $\begin{array}{l}\text { - Equipment purchase and installation } \\
\text { - Equipment purchase for pollutants control } \\
\text { - Supporting equipment } \\
\text { - Spare equipment } \\
\text { - Tools and gear } \\
\text { - Transportation costs } \\
\text { - Equipment modernization }\end{array}$ \\
\hline 1.3. Contingency costs & $\begin{array}{l}\text { Adjustment of work scope according to the working drawings, } \\
\text { developed after the working project approval } \\
\text { Errors in the estimates, revealed after the approval project docu- } \\
\text { mentation } \\
\text { - Changes in the design solutions of construction documents }\end{array}$ \\
\hline
\end{tabular}

2. Operational and maintenance costs

$\begin{aligned} \text { 2.1. Energy costs } & \text { - Coal } \\ & \text { - Natural gas } \\ & - \text { Other fuel types } \\ \text { 2.2. Materials and services } & - \text { Auxiliary materials } \\ \text { costs } & - \text { Tools } \\ & - \text { Production services } \\ & - \text { Environmental protection services }\end{aligned}$


Table 2: Continued

\begin{tabular}{ll}
\hline Costs structure & Costs specification \\
\hline 1 & 2 \\
\hline 2.3. Labor costs & - Workers \\
& - Auxiliary workers \\
& - Personnel training \\
2.4. Repair and & - Cleaning materials \\
maintenance of & - Lubricating materials \\
equipment costs & - Cooling agents \\
& - Spare parts, components \\
2.5. Indirect costs & - Insurance premium \\
& - License fees \\
& - General business costs
\end{tabular}

3. Separately considered costs

- Taxes and fees for the natural resources usage

- Payments for negative impact on the environment

- State duties for necessary licenses and permits

- Development costs on environmental documentation

- Fines

- Potential damages

- Supplementary costs, caused by changes in market conditions and other unforeseen factors

producers (suppliers); consultants, research groups; energy sector development plans; authorities; published information (papers, reports of engineers, sites of the power complex companies, data from conferences); costs assessment of the comparable projects in other industries [17].

Stage 8. Determination of the cost structure of technologies implementation: The main task of this stage is to determine which elements of the costs should be included or excluded from the assessment. This stage helps to understand the cost structure and items to which costs are allocated.

Stage 9. Revenue assessment: It is necessary to collect information on additional income that may arise with the BAT implementation: (1) Sales revenues: sale of purified sewage effluent; sale of ash wastes; sale of additionally produced electricity. (2) Avoided costs: saving of raw materials and basic materials; saving of auxiliary materials; saving of labor costs; saving due to emissions (discharges) monitoring; reduction of emissions (discharges); reduction of emissions (discharges) costs; reduction of the indirect costs on environmental components rehabilitation; reduction of the indirect costs on population health recuperation and related production losses. (3) Following benefits: Introduction of the new technology may lead to changes in the production process, which will affect production costs or the quality of the results. The obtained benefits are difficult to estimate, but it is necessary, if possible, to identify them and include into income data.

Stage 10. Processing and presentation of information on costs and revenues: The collected information on costs and revenues should be processed in such a way that it would be possible to 
objectively compare alternatives. It is possible to formulate the most significant moments of information processing and presentation: (1) data calculation and presentation in the form of annual costs and revenues; (2) stating cash flows in a single currency (rubles for the Russian Federation); (3) adjustments for inflation effects; (4) initial data presentation in the base-year prices; (5) real prices usage in the calculations; (6) use the cash flows discounting method; (7) valid approach to the discounting rate determination $[16,17]$.

To assess the investment and operational costs, the calculation conditions will be considered similar in the framework of the common legislation and normative and methodical basis on the national (international) level. For the data collected for companies, technologies, projects implemented, for example, in the EU Member States or the other countries, it is necessary to take into account the existing differences during the economic calculations to justify the BAT implementation in the conditions of the Russian Federation.

Any made assumptions, coefficients and indexes should be stated in the basis to provide for clarity. To consider the regional differences in economic indexes of the construction and installation works costs, raw materials and components costs, it is necessary to use normative and methodical requirements of the construction documentation of the Russian Federation.

To account for the regional differentiation in the producers' prices change indexes, it is essential to use the official statistics of the Russian Federal State Statistics Service of accounting for prices changes in the economy according to the regional factors [17]. The used indexes and sources should be clearly identified in the basis of the project.

Stage 11. Evaluation and comparison of alternative technologies: After the benefit for the environment and the economic costs on the implementation have been established for the alternatives (technologies), it is necessary to fulfill a comparative analysis and to determine which technology meets the BAT criteria $[15,16]$. Certainly, the final decision will be based on expert opinion, which can be acquired with the help of the approaches, described below. Economic efficiency is certainly important for the BAT determination, and in this aspect it is necessary to find out which of the considered technologies provides for the greatest environmental benefits at the lowest financial cost.

There are several major ways to determine the cost-effectiveness with reference to the Russian energy sector companies: the cost-effectiveness analysis; the costs allocation between the pollutant emissions (discharges); the comparison of the costs on the technologies introduction and environmental benefits. The evaluation of the alternative technologies using these methods can help to achieve clarity and consistency in decision-making.

Economic effectiveness analysis: In the context of ecological policy, this method means the achievement of the highest ecological results for every ruble invested into the environmental measures.

The most obvious way to compare the costs of the activity realization and the gained benefits consists in presenting them in the pecuniary form and comparing them by the analysis of costs and gains. If the comparison shows that the benefits exceed the costs, then the activity is worth investing into. If the different alternative measures bring the positive results, then the highest evaluation should be given to the activity with the best 'costs/quality' ratio. Though such an analysis requires the large amount of data, some benefits are difficult to present in the pecuniary form.

The costs efficiency analysis is simpler than costs and gains analysis as in this case the ecological benefits are assessed quantitatively and not in money terms. Usually, this type of analysis is used to find out which of the measures are the most preferable while achieving the certain ecological purpose at the lowest cost. The economical effectiveness is defined by the following:

Economical effectiveness $=$ annual costs/emissions (discharges) decrease. 
In the context of the BAT determination, the use of the economical effectiveness approach is not enough. But the ranking of the BAT variants by their economical effectiveness value is useful, e.g. for excluding the variants that are extremely costly comparing to the ecological benefit gained.

The allocation of the costs between the polluting emissions (discharges): This brings the additional information regarding the methods of the costs allocation between the polluting substances the ingress of which into the environment should be prevented or decreased. If the costs related to the environmental technologies were allocated between the polluting substances than the method of their proportional distribution should be described. There are two possible approach to the costs allocation:

1. The costs of the technology (equipment) may be fully allocated to the same problem of the environment pollution, for which this activity was initially intended. Then, the decrease of the other pollutants discharges will be considered, the additional benefit for the environment as it did not require the additional costs.

2. The scheme of the cost apportionment may be created to allocate the costs between the pollutants, the impact of which on the environment provokes the concerns.

While evaluating the technologies the first approach is the most useful. If the second approach is used, then the report should contain a clear description of the applied methodology to provide for the transparency and completeness of the estimates.

The comparison of the technologies introduction costs and environmental benefits: The technology will be considered effective if the environmental benefits will exceed its implementation costs.

The cost-effectiveness of the technology introduction $=$ The sum of the discounted income/the sum of the discounted costs. But in this case, there are certain difficulties with the justification of the discount rate and the amounts of revenues and expenses for an extended period of time. But even considering these difficulties, according to the authors, the method is the most preferable and reflects epy reality most accurately.

It should also be considered that usually the only criterion for the new units is the overall economic efficiency. For the existing units, the overall costs should be evaluated along with the marginal cost-effectiveness of the technology implementation, which is defined as the ratio of marginal costs and marginal effect.

In this case, it is impossible to consider all the features and nuances that occur in the real situation. But the approaches presented at this stage will help develop a well-thought opinion about the balance between costs and benefits.

The proposed algorithm of the BAT implementation by the energy sector companies is shown in Fig. 3.

The technology identified as BAT should be developed on such a scale which allows its implementation in the relevant industrial sector, under economically and technically valid conditions. The authors attempted to clarify the scope of the problem while trying to determine whether the technology implementation for a specific industry is economically valid. The assessment of the economic efficiency is only necessary with BAT determination at the industry level, when the proposed technologies lead to the fundamental changes in the energy sector.

\section{EVALUATION OF THE TECHNOLOGIES ECONOMIC VIABILITY IN THE ENERGY SECTOR}

The reference book [15] and the national standard of the Russian Federation [18] provide general recommendation on the assessment of the technologies economic cost-effectiveness in various industry sectors. In this article, the authors focus on the peculiarity of such assessment in the energy 


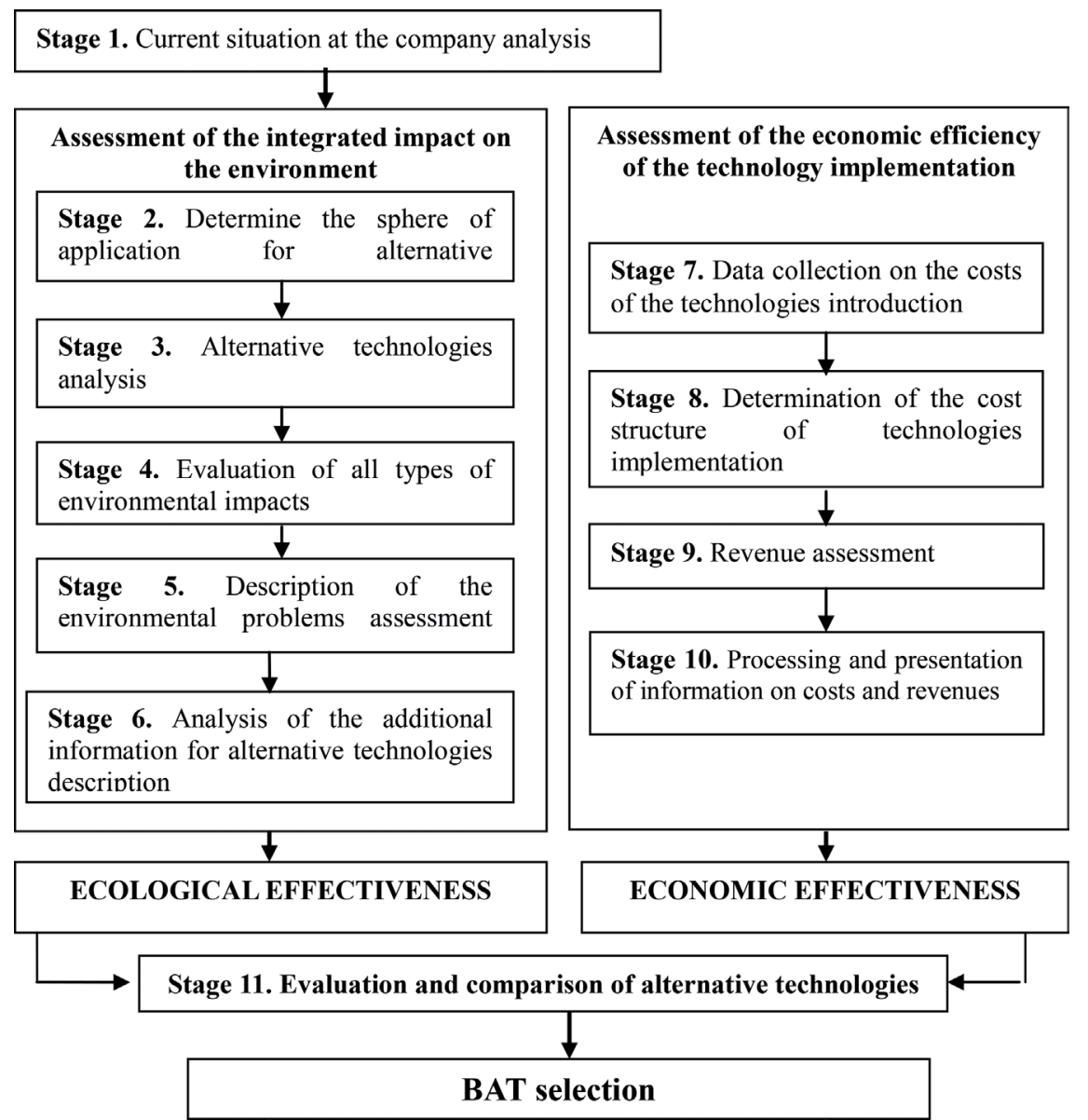

Figure 3: Algorithm of the BAT selection by the energy sector companies.

sector. In the authors opinion, this approach will allow a better understanding of the existing differences in the types of resources, peculiarities of raw materials, the availability of different energy types, natural conditions, environmental and production characteristics of the areas and a better disclosure of the BAT transition concept.

To assess the economic cost-effectiveness and the implemented technology viability in the energy industry, certain critical factors that will help to structure the economic aspect of the BAT implementation, are proposed for consideration (Fig. 4).

It is assumed that for the consideration of the economic cost-effectiveness assessment at the industry level, the most significant problems are: (1) industry structure; (2) market structure; (3) the ability of quick recovery ('elasticity') and (4) implementation rate [15,18].

The structure of the (energy) industry describes the socio-economic characteristics of the considered industry and the technical characteristics of the industry companies. These characteristics allow a better understanding of the industry structure and how easily can the BAT implementation pass. While describing the structure of the industry, it is logical to consider the following questions: 


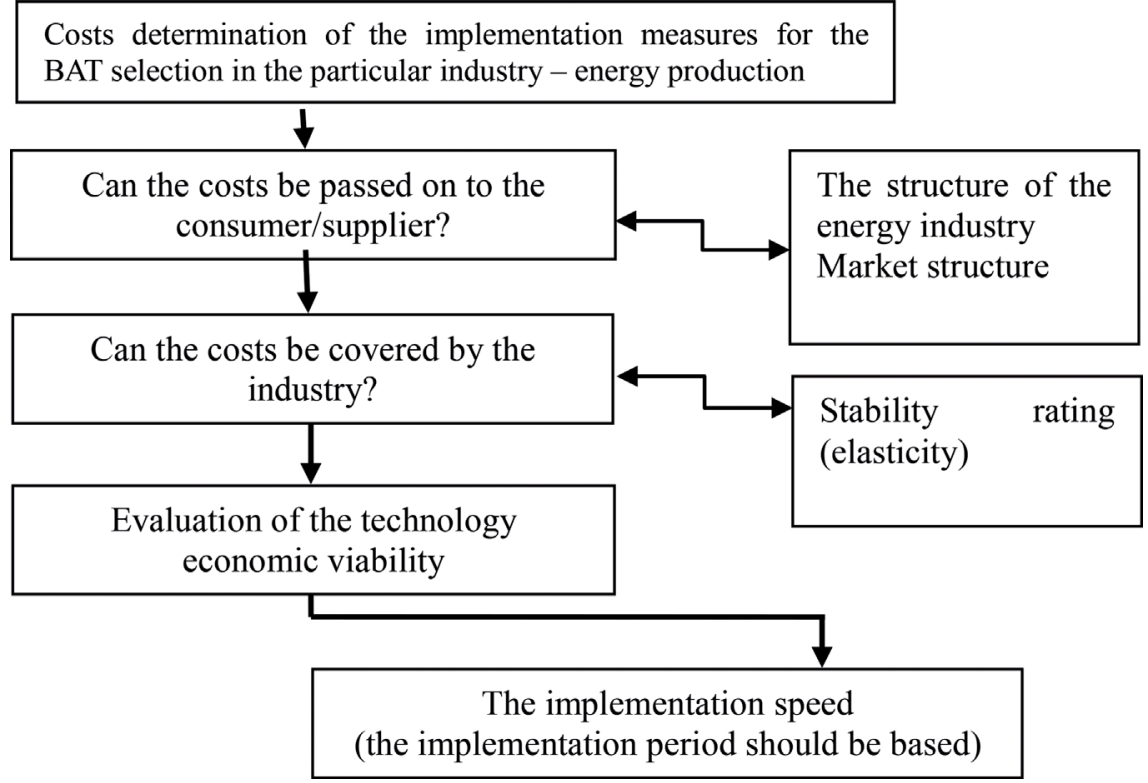

Figure 4: The evaluation of the BAR implementation economic cost-effectiveness in the energy sector.

1. The size and number of the companies in the industry: Large companies are common for the energy industry. The companies of different sizes may respond differently to the BAT introduction - larger companies may eventually make significant savings, but the capital costs of the equipment are usually high, and a sufficiently long period of time is required to replace the equipment.

2. Companies (units) specifications: The existing infrastructure of the company will have some impact on the BAT type and can also affect the implementation costs of this technology. Improvements on the 'end-of-pipe' (pollution control equipment) initially may be relatively cheap and quick to install, but in most cases, such solutions result in increase of the operational costs and are not as effective as measures, integrated into the technological process of production. On the other hand, technological improvements (BAT), integrated into the technological process, or the transition to the low-waste technology can be expensive due to the need to stop the production and practically reconstruct the whole process.

3. Equipment service life: The equipment with long service life is usually used in the energy sector. It is a determining factor in the investment cycle. In such cases, the decision contributing to the BAT cost-effective implementation may become the establishment of the introduction terms, coinciding with the replacement terms of the equipment and the period for which modernization investments are planned.

4. Barriers for market entry or exit. In cases when there are barriers for the new players' entry into the market (e.g. high prices for equipment or licenses), the problem of technical barriers should be considered separately.

During the assessment of the BAT implementing cost-effectiveness, the understanding of the industry structure can help to identify any constraints that may complicate the proposed BAT implementation. 
The market structure can affect the ability of the company in terms of the transfer, assignment of the 'environmental' costs of the BAT implementation on to the consumers or suppliers. The costs can be passed on to the consumers by the products price increase. Or, on the contrary, the costs can be passed on to the supplier by reducing the raw materials prices due to the need to improve environmental effectiveness. There is a range of factors, characterizing the market structure for the energy sector. Many of these factors are associated with a qualitative assessment, which makes it difficult to determine their effect on BAT; but among them, the most important factors can be marked:

1. The market size: Most likely, in relation to the energy sector the local and regional markets are considered. On the local market, the consumer could rely on the producer and may have limited control over the price. This is less true in the case of the global market where prices are determined on the open market and the European operators should stay competitive in relation to the producers outside Europe [15].

2. The price elasticity: In case of the energy sector, the prices are usually inelastic and costs can be transferred to the consumer relatively easy. However, the considered companies are limited in the energy sources prices growth; therefore, there are certain difficulties with the costs growth and its transfer to the consumer.

3. The competition between the products: On the market where the goods are produced in plenty and the differences between them are irrelevant or small, stiff competition exists. This is true for industries such as power sector, where the ability of the companies to establish (or increase) the prices is insignificant.

There are several methodologies for the markets analysis. One of the traditionally used methodologies is Five Forces Analysis by Michael Porter. The competitive forces determine the industry profitability because they influence the prices, costs and required investments in the industry. The size and the ratio of these forces vary in different industries and can change as the industry develops [15].

The analysis of the market structure facilitates the significant risks identification and allows industry to consider the impact of these risks (if any) for the BAT definition.

The industry stability (elasticity): The elasticity reflects the ability of the industry to cover the increasing costs of the BAT implementation, while maintaining its profitability in the short, medium and long term. Any increase in costs associated with the BAT implementation should be covered by the industry or passed on to the consumer. The elasticity describes the ability of the industry to cover these costs. To describe the elasticity, the following group of the financial indexes can be used: liquidity; solvency and profitability. To describe the elasticity of the industry, it is useful to consider the long-term trends (5-10 years) to ensure that short-term fluctuations do not affect the BAT determination.

The implementation speed: If after assessing the industry structure, market structure and stability of the industry certain doubts about the idea of BAT remain, the technology implementation speed can be estimated as the implementation time can be critical for the energy sector. The implementation speed normally is not an issue for the new facilities (as opposed to active) because it is expected that new companies are ready to use environmentally safe technologies and pollution control equipment. Therefore, the evaluation process should distinguish new and existing enterprises.

To determine the BAT implementation speed, it is useful to consider the following time scales: Short-term (several weeks or months): For many decisions, the time period required for the implementation does not need a special discussion. Usually, these solutions can be implemented quickly and often require small costs (raw materials replacement, small pollution control equipment 
installation or management system improvement). Medium-term (from a few months to a year): There are certain technologies that may require a longer period of implementation, so it is necessary to take into account or schedule the costs ('end-of-pipe' technological solutions). Long-term (several years): In those cases when significant changes of the production process or reconstruction of the company are required, the capital costs are usually quite substantial. The modernization time should coincide with the planned replacement of existing equipment, and investment cycles can be effective tools for the cost-effective technology implementation.

The speed of the BAT implementation is one of the limiting factors for the energy sector, especially with the more expensive technologies introduction. Then, to ensure cost-effectiveness of any modernization with the equipment replacement, it should be linked to the investment cycle of the company. This factor should be taken into account to find a balance between the environmental protection interests and the peculiarities of the energy companies investment cycles.

\section{CONCLUSIONS}

The economic cost-effectiveness is an integral part of the BATs concept. But its profound assessment should be carried out only in cases when there are clear differences regarding which BAT can be implemented cost-effectively in the energy sector. Strict and unambiguous rules cannot be applied to all power sector companies, under BAT. Therefore, the evaluation of economic cost-effectiveness is not an easy or quick process.

Understanding of what factors are the most critical for the energy sector allows the decisionmakers to identify the optimum ratio and select BAT, which can provide a high protection level of the environment on the whole and, at the same time, would not threaten the industry viability and stability.

The approaches considered by the authors are quite reliable and form a structure for the decisionmaking process. Concept of the transition to BAT presented in this article should help to clear state the existing aspects, to justify the costs and benefits of the technologies implementation and ensure the further energy companies development.

\section{REFERENCES}

[1] Federal Law no. 219 of 21 July 2014. On Amendments to the Federal Law 'On Environmental Protection' and Certain Legislative Acts of the Russian Federation [Digital source], available at: http://www.rg.ru/2014/07/25/eco-dok.html.

[2] Official website of the Federal State Statistics Service. Statistical Yearbook. [Digital source], available at: http://www.gks.ru/bgd/regl/b14_13/IssWWW.exe/Stg/d02/14-51.htm.

[3] State report, 'On the State and Environmental Protection of the Russian Federation in 2013'. [Digital source], available at: http://www.mnr.gov.ru/regulatory/list.php?part=1683.

[4] The Energy Strategy of Russia for the period until 2030, approved by the Government Decree no. 17-15-r of November 13, 2009 [Digital source], available at: http://minenergo.gov.ru/ aboutminen/energostrategy.

[5] Directive 2010/75/UE (IED) [Digital source], available at: http://ec.europa.eu/environment/ industry/stationary/ied/legislation.htm.

[6] Directive 96/61/EC (IPPC) [Digital source], available at: http://eur-lex.europa.eu/LexUriServ/ LexUriServ.do?uri=CELEX:31996L0061:en:HTML

[7] Reference Document on Best Available Techniques for Large Combustion Plants, European Commission, 2006.

[8] Handbook on best available techniques for large fuel combustion plants (transl.) [in Russian], SE 'INVEL': Moscow, 2009. 
[9] Handbook on best available techniques for the efficiency increase and negative impact decrease in the heat power sector (transl.) [in Russian], Moscow, 2009 [Digital source], available at: http://www.14000.ru/projects/lcp/Reference_Book_2008.pdf.

[10] Main regulations (Concept) of the technological policy in the power sector of Russia until 2030, RAO 'ES of Russia' 2008.

[11] Abramov, V.V. \& Putilov, V.Y. (eds), Modern Technologies in Power Industry: Information Digest [in Russian], MEI Publishing House: Moscow, 388 pp, 2007.

[12] The UN Economic Commission for Europe Protocol to Abate Acidification, Eutrophication and Ground-level Ozone [Digital source], available at: http://www.unece.org/env/lrtap/multi_ h1.html.

[13] The UN Economic Commission for Europe Kiev Protocol on Pollutant Release and Transfer Registers [Digital source], available at: http://www.unece.org/env/pp/prtr.html.

[14] European Pollutant Release and Transfer Register (E-PRTR) [Digital source], available at: http://prtr.ec.europa.eu.

[15] Economic aspects and impacts on different components of the environment. Reference Document on Best Available Techniques, [in Russian], Project 'Harmonisation of environmental standards HES II, Russian', 2006, available at: http://14000.ru/brefs/BREF_ECME.pdf.

[16] Sokornova, T., Korolev, Y., Sergienko, O. \& Kryazhev, A., Economic aspects of the BAT implementation. Ecology of Production, 10, pp. 28-35; 11, pp. 44-49, 2012.

[17] Berezyuk, M., Rumyantseva, A., Merzlikina, J. \& Makarova, D., The development of an ecological-economic substantiation algorithm for BAT selection for companies within the power industry. WIT Transactions on Ecology and the Environment, 190(2), pp. 1161-1172, 2014. doi: http://dx.doi.org/10.2495/eq141082

[18] National standard of the Russian federation, resources saving. Identification methodology, available at: http://docs.cntd.ru/document/gost-r-54097-2010. 